\title{
Can Chinese Companies Still Invest in the United States? The Impact of FIRRMA
}

\author{
Paul B. Edelberg \\ Fox Rothschild LLP, New York, USA
}

\begin{abstract}
The Foreign Investment Risk Review Act, or FIRRMA, signed by President Trump on August 13, 2018, significantly expanded the scope of transactions involving foreign investment in U.S. companies that are covered by the national security laws of the U.S., commonly known as the CFIUS regime. Certain minority investments and certain technology-related investments may now need to be submitted to the Committee on Foreign Investment in the U.S. (CFIUS) for clearance. FIRRMA also implements an expedited filing process, which in some cases is mandatory, and expands the authority and enforcement tools of CFIUS. This new law in part targets China's investments in the U.S. and its attempts to procure U.S.-based technology. This article discusses the new law and analyzes the implications of the law on Chinese investment in the U.S.
\end{abstract}

Keywords: CFIUS, FIRRMA, critical technologies, emerging and foundational technologies, minority investments, foreign acquisitions, declarations, national security

On August 13, 2018, President Trump signed a comprehensive defense bill, now known as the John S. McCain National Defense Authorization Act for Fiscal Year 2019 (the "NDAA"). ${ }^{1}$ One part of the NDAA consistes of the Foreign Investment Risk Review Act, or FIRRMA. ${ }^{2}$ FIRRMA made significant changes to the Exon-Florio provisions of the Defense Production Act of 1950, as amended by the Foreign Investment and National Security Act of 2007 (the "Pre-FIRRMA Law"), the law which created the Committee on Foreign Investment in the United States, commonly known as "CFIUS" or the "Committee". The Committee is the regulatory body that reviews foreign investments into the U.S. to determine if they threaten the national security of the United States.

For those not familiar with the Pre-FIRRMA Law, a foreign company seeking to acquire a controlling interest in a United States business may voluntarily file a notice with the Committee for a determination of whether the prospective ownership by the foreign investor threatens national security. The Committee then conducts a review and, if the acquisition has national security implications, the Committee can then conduct a more in-depth investigation. If the Committee makes a determination that national security will be threatened, it can recommend to the President that it block the transaction unless the transaction is abandoned by the parties or unless the Committee and the parties enter into an agreement (a "mitigation agreement") to place conditions on the acquisition to overcome the national security concerns.

Paul B. Edelberg, partner in the New York City Office of Fox Rothschild LLP; co-chair of the Central/East Asia \& China Committee of the Section of International Law of the American Bar Association, Chicago, USA.

1 Pub. L. No. 115-232, 132 Stat 1636 (2018) (“NDAA”).

2 NDAA, Subtitle A, Secs. 1701-1728. 
With certain exceptions, the filing is voluntary. However, if a foreign acquirer does not file a notice with the Committee and subsequently the Committee learns of the transaction and conducts a post-closing investigation, which investigation results in the President's blocking the transaction, the Pre-FIRRMA Law empowers the Committee to unwind the acquisition transaction, which can be an extremely disruptive event.

FIRRMA makes substantial changes in the Pre-FIRRMA Law and is in large part in response to the Trump Administration's concerns over Chinese investment in the U.S. and the perceived transfer of U.S. technology by Chinese investors. While for most part, China is not mentioned by name in FIRRMA, the intent is clear and has been trumpeted by the President and Congress as an effort to prevent Chinese private and government-controlled entities from acquiring U.S.-developed technology to the long-term competitive disadvantage to the U.S. economy. The Trump Administration has expressed its concern over President Xi Jinping's "Made in China 2025” initiative and its potential competitive impact on the U.S.

\section{Overview}

FIRRMA significantly expands the scope of the Pre-FIRRMA Law. The legislation states the objectives of FIRRMA, as follows:

- To protect the national security of the U.S. as it relates to critical infrastructure and critical technology;

- To curtail transfer of technology to Chinese companies;

- To curtail obtaining and exploiting sensitive personal data by foreign governments and persons;

- To protect personally identifiable information and other sensitive data from foreign governments and persons;

- To protect from cybersecurity vulnerabilities by foreign governments and persons and to curtail interference with U.S. elections. ${ }^{3}$

Changes to the Pre-FIRRMA Law by FIRRMA can be summarized as follows:

1. It expands coverage to a new group of transactions.

2. It codifies existing practices of the Committee.

3. It implements a new procedure for filing "declarations".

4. It lengthens the CFIUS review period.

5. It provides additional funding for the Committee.

6. It creates a "stipulation" process.

7. It mandates periodic reports on Chinese investments in the U.S.

8. It establishes a process for identifying and controlling export of "emerging and foundational technologies".

The effective date of FIRRMA will depend upon the particular provision. Most of the procedural provisions take effect immediately. The coverage and jurisdictional provisions (i.e., the substantive provisions) take effect upon the earlier of February 13, 2020 or 30 days after the publication in the Federal Register by Treasury Department that regulations, organizational structure, and resources are in place. ${ }^{4}$

\section{Key Concepts}

There are several key concepts to understand in this discussion of FIRRMA.

\footnotetext{
3 NDAA Sec. 1702 (c).

${ }^{4}$ NDAA Sec. 1727.
} 
The term "investments" includes contingent equity interest acquisitions. ${ }^{5}$ This covers convertible debt and contractual rights that would result in a de facto acquisition. This is a clarification of existing CFIUS practice.

The term "covered transaction" means a transaction that is within the scope of CFIUS and subject to review by the Committee. ${ }^{6}$

The term "United States Business" means a person engaged in interstate commerce in the United States. Note that this term was not defined in the existing Pre-FIRRMA Law, but is defined in the existing CFIUS regulations. However, the CFIUS regulations qualify that definition by limiting such a person only "to the extent of its activities in interstate commerce". ${ }^{8}$ It is not clear whether FIRRMA intended a broadening of this definition, or whether the regulations under FIRRMA will keep the same regulatory definition and scope.

\section{Covered Transactions}

Existing Pre-FIRRMA Law applies to acquisitions of a controlling interest in a United States Business. FIRRMA adds the following transactions in addition to the existing control transactions to the list of "covered transactions" subject to CFIUS:

- Minority non-passive investments;

- Ownership, leases, and “concessions” of real estate;

- Changes in a foreign investor's rights in a "United States Business";

- Mergers and acquisitions carried out through joint ventures;

- Schemes to evade CFIUS.

The following is a discussion of each new category of "covered transaction".

\section{Minority Non-passive Investments ${ }^{9}$}

FIRRMA brings minority investments that are not passive investments into the CFIUS realm. There are two basic tests to determine whether the transaction is a minority non-passive investment. The first test is a passivity test, which is embodied within the definition of "other investment". The second is a test on whether the CFIUS criteria for national security threats exist.

Passivity test. If the minority acquisition affords the foreign investor any one of the three following rights, then the minority acquisition will not be considered passive and will be treated as an "other investment":

1. Access to "material non-public technical information” of the United States Business,

2. Board or equivalent membership or observer rights in the United States Business or the right to nominate such a person,

3. Any involvement, other than through voting of shares, in substantive decision-making of the United States Business regarding critical technologies, critical infrastructure or sensitive personal data of U.S. citizens maintained by the United States Business, as discussed below.

"Material non-public technical information" is defined as non-public information about the critical technologies and critical infrastructure of the United States Business, but excludes financial information of such business.

\footnotetext{
5 NDAA Sec. 1703 (a) (9).

${ }^{6}$ NDAA Sec. 1703 (a) (4).

7 NDAA Sec. 1703 (a) (13).

831 C.F.R. Sec. 800. 226.

9 NDAA Sec. 1703 (a) (4) (B) (iii).
} 
The term "other investments" includes direct and indirect investments, meaning that transactions conducted at the parent level or other higher intermediate level are encompassed within this definitional term. They do not include controlling acquisitions already subject to existing Pre-FIRRMA Law.

Investment fund carve-out ${ }^{\mathbf{1 0}}$. The passivity test is of paramount importance to private equity and investment funds. Foreign investment funds provide essential capital to emerging technologies and other U.S. enterprises. If foreign money, and in particularly Chinese money, participates in a fund, that fund runs the potential of subjecting any acquisition of a United States Business by the fund subject to CFIUS review, depending upon whether any national security activities (as discussed below) are involved in the United States Business. Therefore, a fund wants to avoid falling within the definition of "other investments".

The stated intent of FIRRMA is to impose national security review of only those investments that are warranted and not to otherwise impede the flow of foreign capital into the U.S. It recognizes that some limited partners and similar investors may demand board representation or some sort of observer or advisory role in connection with their investments in a fund. In recognition of this, FIRRMA creates a narrow carve-out (the "fund investment carve-out"), from the prong of the passivity test that prohibits board or equivalent membership or observer rights of the United States Business or the right to nominate such a person.

The criteria for the carve-out, subject to further clarification in the Committee regulations, are as follows:

- The fund must be managed exclusively by a U.S. general partner (which term is used by this author to encompass a general partner, a managing member, a manager, or the equivalent);

- The foreign person may serve on an advisory board or committee of the fund (not of the United States Business) if:

- The foreign person is a limited partner or the equivalent;

- The board or committee does not have the ability to influence investment decisions of the fund or to influence decisions made by the general partner related to the target entity;

- The foreign investor does not otherwise have the ability to control the fund, which term is defined to include the ability to influence investment decisions of the fund, to influence decisions made by the general partner related to the target entity, or to unilaterally control the dismissal or replacement of the general partner or its compensation;

- The foreign investor does not have access to material, non-public technical information as a result of its participation on the advisory board or committee of the fund.

Note that a seat on the advisory board or committee of the United States Business does not qualify for this carve-out exemption. Moreover, the other two prongs of the passivity test, which are the no-access to material non-public technical information of the United States Business and no involvement in substantive decision-making of the United States Business regarding national security activities, still must be satisfied for a fund to meet the passivity test.

Even if a fund does not satisfy the passivity test, it can still proceed without national security review by CFIUS if it does not fall within the criteria under the national security test.

National security test. The second test for minority non-passive investments is what can be called the "national security test”. Only acquisitions of a United States Business that is involved in any one or more of the three following activities (which this author calls "national security activity" for purposes of this article) can be

10 NDAA Sec. 1703 (a) (4) (D) (iv). 
blocked under the CFIUS process. A United States Business must be engaged in one or more of the following activities to constitute a national security activity:

- own, operate, manufacture, supply, or service critical infrastructure;

- produce, design, test, manufacture, fabricate, or develop critical technologies;

- maintain or collect sensitive personal data of U.S. citizens that may be exploited so as to threaten U.S. security.

The "critical infrastructure" terminology is the same as under Pre-FIRRMA Law, although one can argue that the Committee has interpreted that language more broadly in the last year or so. We will have to see if the Committee regulations will expand the interpretation beyond the existing law. It should be noted that FIRRMA mandates that the indicia of critical infrastructure in the regulations must "likely be of importance to the national security of the United States”, which can be interpreted as a directive to limit the definition only to types of critical infrastructure that are truly of national security importance.

The regulations under current Pre-FIRRMA Law ${ }^{11}$ have an almost identical definition of "critical technologies" as in FIRRMA, with one important exception. Under the current regulations, there are four specific categories dealing with munitions, nuclear proliferation, and the like. FIRMMA adds a fifth category, "emerging and foundational technologies", as an additional basis. An interagency process has been established to identify through regulation what technologies constitute "emerging and foundational technologies". This is a significant add-on, as it attempts to regulate the transfer of technology to other countries and in particular to China. This criterion will also impact investment funds seeking foreign money, since emerging technologies are often the target of foreign investment. The only way to eliminate this uncertainty is to come within the passivity requirements discussed above so that requirement for a national security review is never reached.

As discussed below, the definition of "emerging and foundational technologies" is to be defined through an interagency process led by the U.S. Department of Commerce in relation to imposing export controls, and the definition under the export regime will be binding on the definition of critical technologies for purposes of CFIUS. On November 19, 2018, the Bureau of Industry and Security ("BIS") of the Department of Commerce published in the Federal Register a proposal seeking comment by December 19, 2018 on criteria for defining and identifying "emerging technologies" for the purpose of imposing export controls, most likely in the form of export licenses or of prohibitions against exports of certain emerging technologies. ${ }^{12}$ It listed 14 categories of emerging technologies (e.g., biotech, artificial intelligence, and microprocessor technology) that are currently subject to export restrictions ${ }^{13}$ and requested public comment on additional categories to be added to the list. The proposal indicates that the emerging technology must be "essential to the national security of the United States" to warrant consideration for export controls and, by incorporation, in the CFIUS process. The proposal also states that BIS intends to issue a similar proposal to seek comment on foundational technologies.

The third criterion, dealing with sensitive personal data, is a new criterion, which has been added in light of technological advances and cybersecurity.

\section{U.S. Real Estate ${ }^{14}$}

The next three new categories of "covered transactions" do not contain any special carve-out for

\footnotetext{
1131 C.F.R. Sec. 800. 209.

1283 Fed. Reg. 58,201 (2018).

1315 C.F.R. Sec. 744.

14 NDAA Sec. 1703 (a) (4) (B) (ii).
} 
investment funds. The first of these three categories is the ownership, lease, or "concession" of certain real estate. To be a covered transaction, that real estate has to be either located within or functioning as part of maritime ports or airports or presenting national security threat to sensitive military or other government facilities. The latter is defined as either: (i) in "close proximity" to such facilities; (ii) reasonably allow eavesdropping or the collection of intelligence from such facility; or (iii) could expose national security activities (as defined above) at such facility. The Committee may prescribe additional other criteria under these standards.

These standards are more or less codifications of existing Committee practices. In the famous Ralls case, ${ }^{15}$ the Committee recommended disapproval of the acquisition of property by a Chinese company near a sensitive military installation.

\section{Changing Investment Rights ${ }^{16}$}

The next new category of covered transactions is a change in investment rights. A change in a foreign investor's rights in a United States Business will be considered a covered transaction if that change could result in either foreign control of the United States Business or an "other investment" (i.e., minority non-passive investment). In other words, a change in a foreign investor's rights that did not initially fall within the "covered transaction" definition and that, through later investments or changes in investor rights that would have constituted a "covered transaction" had they been in place initially will trigger "covered transaction" status.

This new category of covered transactions is also relevant in the fund context where a limited partner is later given rights, such as a board seat on the United States Business or rights to control investment decisions.

\section{Joint Ventures ${ }^{17}$}

Joint ventures are now clearly covered transactions. This new category of covered transactions was added to clarify existing Committee practice. A number of off-shore joint ventures, including Chinese joint ventures, have been formed in the past where the U.S. company or parent transferred its assets to the off-shore joint venture to avoid CFIUS. This practice is now recognized as a covered transaction. Unlike the other substantive provisions discussed above, this provision is effective immediately and applies to transactions since 1988, when CFIUS was last amended.

\section{Schemes to Evade CFIUS ${ }^{18}$}

This standard covers transactions, transfers, agreements, and arrangements and to a certain extent mirrors existing Committee practice. Committee regulations will further define the standards for this new category of covered transactions and specify the types of transactions to which this applies.

\section{Country Specifications ${ }^{19}$}

FIRRMA directs the Committee to promulgate regulations that will relax the minority investment and real-estate-covered transaction requirements for foreign persons from certain countries. The prefatory language in FIRRMA encourages the promotion of reciprocal treatment for foreign direct investment with allies of the United States, while at the same time authorizing the Committee to consider "whether a covered transaction

\footnotetext{
15 Ralls v. Committee on Foreign Inv. In U.S., 758 F.3d 296 (D.C. Cir. 2014).

16 NDAA Sec. 1703 (a) (4) (B) (iv).

17 NDAA Sec. 1703 (a) (4) (B) (i).

18 NDAA Sec. 1703 (a) (4) (B) (v).

19 NDAA Sec. 1703 (a) (4) (E).
} 
involves a country of special concern that has a demonstrated or declared strategic goal of acquiring a type of critical technology or critical infrastructure that would affect United States leadership in areas related to national security”. While China is not specifically mentioned, the reference is obvious. One can expect that Canada, Mexico, European allies of the U.S. and Japan will be given lenient treatment in the final Committee regulations.

\section{Procedural Amendments}

\section{Mandatory Declarations}

FIRRMA establishes an alternative filing mechanism called a "declaration", which is an abbreviated short-form filing for expedited determination. ${ }^{20}$ Upon filing of a declaration, the Committee can require the filing of a full-blown notice, or in some instances, a short form declaration will suffice. Since the declaration process in general is not aimed at Chinese investment, the author will focus on only one component that is focused in part on Chinese government and state-owned entity (SOE) investment.

While the declaration is a voluntary filing in most instances, FIRRMA does mandate the mandatory filing of declarations in certain circumstances. ${ }^{21}$ FIRRMA mandates that the Committee prescribe by regulations the types of covered transactions for which a mandatory declaration will be required, and the statute sets forth a general basis for requiring mandatory declarations. An acquirer must file a mandatory declaration in connection with a direct or indirect acquisition "of a substantial interest in an unaffiliated United States business by a foreign person in which a foreign government has a direct or indirect substantial interest”. This applies only if the United States Business controls critical infrastructure, critical technology, or sensitive personal data. It should be noted that there are two "substantial interest" tests. The first is that the foreign government must have a substantial interest in the foreign acquirer. The second is that the acquisition must be of a substantial interest in a United States Business.

Any investment of less than 10 percent voting interest in and of itself is presumed not to constitute a "substantial interest". A "substantial interest" can also be triggered if the foreign government can influence the actions of a foreign person" This could be by board membership, significant ownership interest, certain shareholder rights, and the like.

Once again, the mandatory declaration filing requirement applies not only to direct investments, but also to indirect investments. One would interpret this to mean government investments transacted in that government's jurisdiction in entities based in that jurisdiction. Such an investment that would cause a change in investment rights and that qualifies as a covered transaction may occur without realization of a mandatory declaration filing or may go undetected by the Committee. Imagine a minority investment that had undergone the CFIUS process successfully, but in which the ultimate parent accepts after the effective date of FIRRMA a 25 percent investment from an SOE within its own country. If the subsidiary has a substantial interest in the United States Business, the SOE investment could very well trigger a mandatory filing.

There is no question that Chinese investment was a primary focus of this mandatory filing requirement and that the regulations most likely will encompass SOEs.

\footnotetext{
${ }^{20}$ NDAA Sec. 1706

21 Ibid.
} 


\section{Investment Fund Carve-out ${ }^{22}$}

A narrow exception from the mandatory declaration filing requirement is made for private equity funds and other investment funds. To qualify for that exception, all but one of the criteria for the fund investment carve-out described for minority non-passive investments must be satisfied. The requirement that the foreign person not have access to material, non-public technical information is eliminated in this carve-out exception.

Even if the tests for the investment fund exception are not met, the Committee may waive the mandatory filing requirement if the foreign investor demonstrates that the investment of the foreign investor is not directed by a foreign government and the foreign investor has a history of cooperating with the Committee.

The mandatory declaration filing requirement is not effective until the delayed effective date, with one notable exception. The U.S. Department of Treasury, within which agency the Committee is housed, issued temporary regulations, effective November 10, 2018, implementing what has been termed the critical technology pilot program. ${ }^{23}$ This program requires mandatory declaration filings for "pilot program industry transactions", which are foreign investments in or acquisitions of a U.S. business that produces or designs a critical technology that is or may be used in a "pilot program industry". It does not apply to investments or acquisitions involving critical infrastructure or sensitive personal data. The regulations set forth 27 industry categories as "pilot program industries" that the Committee deemed of critical importance to national security. Therefore, in addition to the traditional operations constituting critical technology, a foreign company directly or indirectly investing in or acquiring a U.S. business that produces or designs an emerging or foundational technology must consider filing with CFIUS. Until the final regulations are issued defining those technologies, one should look to the industry categories in the November 19th proposal and examine potential uses of the technology and file with CFIUS if there is a remote possibility that the technology would be considered an emerging or foundational technology.

\section{Export Controls}

Section 1758 of the Export Control Reform Act of 2018 ("ECRA"), enacted as part of the NDAA in conjunction with FIRRMA, mandates that the Secretary of Commerce establish export controls under the Export Administration Regulations for the export, re-export, or in-country transfer of "emerging and foundational technologies”. ${ }^{24}$ As discussed above, ECRA serves as the basis for defining those technologies through an interagency process as they apply to FIRRMA. By prohibiting or requiring a license for the export of any of these technologies, it also limits and discourages foreign greenfield investments in the U.S. the purpose of which is to develop technologies within the U.S. and then to transfer those technologies to the foreign country.

\section{Conclusion}

FIRRMA changes the CFIUS landscape dramatically by encompassing a broader scope of investment transactions, by mandating early-stage declaratory filings for certain foreign government and SOE investments, and by placing restrictions on foreign investment in and the export of "emerging and foundational technologies”. It also provides additional funding for the Committee and implements more flexible filing

\footnotetext{
22 Ibid.

2383 Fed. Reg. 51,322 (2018).

${ }^{24}$ NDAA Sec. 1758.
} 
procedures. This will empower the Committee to have greater oversight and control over foreign investment in the U.S.

The Act also makes clear that FIRRMA is not intended to close the U.S. to FDI, but rather to protect the national security of the U.S. and hinder technology transfers to certain countries, particularly China. It directs the Committee to circumscribe its regulations to activities of truly national security importance. It encourages reciprocal FDI policies with its allies, and it is anticipated that the Committee regulations will not dramatically alter the current CFIUS process for those allies. It is also this author's opinion that, even for Chinese companies investing in the U.S., and in particular privately owned enterprises (POEs), the Committee will continue to approve Chinese investments that truly do not impact the national security of the United States. The only possible exception is investment in emerging and foundational technologies. We must wait to see how broadly that term is defined and how wide a net it will cast.

Moreover, CFIUS creates a pathway, although somewhat limited, for Chinese investment through U.S. funds. If a U.S. fund does not own, and does not intend to acquire, portfolio companies that engage in national security activities, Chinese investment in that fund is not really affected by FIRRMA. But a significant portion of Chinese investment has been directed towards acquisition of companies with new technologies, some of which may eventually be classified as "emerging and foundational technologies". Moreover, portfolio companies that do not directly engage in national security activities but are vendors for companies that do engage in those activities or sell to the U.S. Government directly may trigger the CFIUS process. For these investments, Chinese companies will need to make passive investments that meet the passivity test discussed above. Otherwise, the U.S. fund risks "poisoning” all of its investments in portfolio companies. 